\title{
PROBLEMS OF THE HUMID TROPICS
}

$\mathrm{T}$ HE Eighth Session of the General Conference of Unesco authorized the Director-General "to promote the co-ordination of research on scientific problems relating to the humid tropical zone and to promote international or regional measures to expand such research". Under this Humid Tropies Programme, a symposium was held at Kandy on methods of study of tropical vegetation in 1955 and a report published; the symposium of wider scope held in Bangkok in November-December 1957 has been reported at length in Nature $(181,596 ; 1958)$. Another obvious first step was to collect information on problems in the tropical regions of member States. Accordingly, three general reports* were commissioned, to be based on available published literature, on the Amazon, the Caribbean, and South Asia, and are now published together with three special reports on biological problems in the Belgian Congo (G. Marlier), entomological problems in South Asia (A. P. Kapur) and water-power in the Philippines (F. C. Rodriguez).

It is difficult to say to whom the general reports are addressed. Dr. F. C. Camargo gives a simple yet interesting account of the Amazon basin, but many of his general statements will be questioned-that the Amazon territory includes examples of all known geological formations, that shifting agriculture is "vicious" and that the Koeppen system of climatic classification should be adopted exclusively. Whereas Camargo ignores much recent work and gives only a dozen references, mainly to local publications, Dr.

- Problems of Humid Tropical Regions. Pp. 102. (Humid Tropics Research.) (Paris: Unesco; London: H.M. Stationery Office, 1958.) 900 French francs; 15 s. ; 3 dollars.
E. Beltran, on the Caribbean, prints a bibliography of nearly 300 items. It is obviously impossible in the space of eleven pages to give other than a most elementary picture of one of the most complex areas in the world.

It is indeed a sad reflexion of the neglect of geography in the educational system of so many countries that what should be background knowledge of any educated citizen has to be the subject of a special report to Unesco. Similarly, apart from lists of tree species, there is nothing in the account of South Asia which does not form part of an undergraduate geographical course on the monsoon lands. Dr. Marlier's five pages on tropical Africa deal only with generalities and have no references, whereas $\mathrm{Dr}$. Kapur's review of entomological problems is a detailed and informative survey of the present position, fully documented by a bibliography of 376 items. Although Dr. Rodriguez's survey of waterpower resources and development in the Philippines, with a folding map showing all sites, seems strangely out of place in this collection, it, too, makes available information not readily accessible.

The editing of the volume is very poor. Innumerable sentences do not even make sense. What, for example, is meant by "Zizyphus are in good order" (p. 47), or "the principal vegetation region is Eugenia" (p. 47) ? Generic names are sometimes given in small letters, sometimes with capitals; misprints such as "depterocarpaceae" are numerous. The map, Fig. 2, has no key, no scale, no orientation ; Figs. 4, 5, 6, 7 and 8 have no scale; the vegetation map, Fig. 6, is described as "Distribution of Climatic Types" and the key is incomplete.

L. Dudley Stamp

\section{EXTREMELY HIGH TEMPERATURES CONFERENCE IN BOSTON}

\begin{abstract}
A CONFERENCE on "Extremely High Temperatures" was held at the New England Mutual Hall, Boston, on March 18 and 19, and was attended by more than 400 members. The Conference was sponsored by the Electronics Research Directorate, Air Force Cambridge Research Center, Bedford, Mass., and members were welcomed by Dr. Lowell M. Hollingsworth, director, Electronics Research. An introductory address was given by Dr. Heinz Fischer, conference chairman, who was assisted by Dr. Lawrence C. Mansur in making the excellent arrangements. The papers were distributed among four sessions : "The Production of Extremely High Temperatures"; "Methods of Temperature Measurement-Optical Radiation"; "Plasma Analysis"; and "Applications".

The production of high-temperature gas by magnetic acceleration was discussed by G. S. Janes and R. M. Patrick (Aveo). When highly ionized deuterium in a cylindrical chamber without electrodes was accelerated towards the axis by an axial magnetic field, and velocities up to $20 \mathrm{~cm}$./ $\mu$ sec. were observed; the influence of magnetic guide fields parallel to the
\end{abstract}

axis and the direction of motion was also investigated. Upper termperature limits in the high-pressure discharge were discussed by Dr. Heinz Fischer (U.S. Air Force). Spark discharges produced by the discharge of a capacitor with minimum self-inductance were described ; the spark-channel temperatures were calculated from the measured spectral radiation density. The gas temperature increased with pressure and reached a limiting value; reduction of inductance raised the limiting temperature. Approximately $250,000^{\circ} \mathrm{K}$. was obtained in helium at thirtyfive atmospheres with a $7 \mathrm{kV}$. spark and with a current density of $10^{6} \mathrm{amp} . / \mathrm{cm} .{ }^{2}$. The effects of electrically exploded wires and the ensuing discharge were described by William M. Conn (Max-Planck Institute, Würzburg), the later stages of the explosion being recorded photographically. Alan D. Morris and Willis C. Gore (Naval Air Test Center) presented an analysis of the thermionic direct current electric arc. Inductive energy storage as a tool for hightemperature research was discussed by $H$. C. Early and R. C. Walker (University of Michigan); for storing electrical energy in the multi-million 